\title{
Nanostructured ZnO as Multifunctional Carrier for a Green Antibacterial Drug Delivery System-A Feasibility Study
}

\author{
Federica Leone ${ }^{1}{ }^{(0)}$, Roberta Cataldo ${ }^{1}$, Sara S. Y. Mohamed ${ }^{1}$, Luigi Manna ${ }^{1}{ }^{(\mathbb{O})}$,

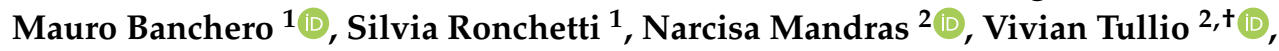 \\ Roberta Cavalli ${ }^{3,+}$ and Barbara Onida ${ }^{1, * \text { D }}$ \\ 1 Politecnico di Torino, Department of Applied Science and Technology, Corso Duca Degli Abruzzi 24, \\ 10129 Turin, Italy; federica.leone@polito.it (F.L.); roberta.cataldo@studenti.polito.it (R.C.); \\ sara.mohamed@polito.it (S.S.Y.M.) luigi.manna@polito.it (L.M.); mauro.banchero@polito.it (M.B.); \\ silvia.ronchetti@polito.it (S.R.) \\ 2 Department of Public Health and Pediatrics, Microbiology Division, University of Turin, via Santena 9, \\ 10126 Turin, Italy; narcisa.mandras@unito.it (N.M.); vivian.tullio@unito.it (V.T.) \\ 3 Department of Drug Science and Technology, University of Turin, via Pietro Giuria 9, 10125 Turin, Italy; \\ roberta.cavalli@unito.it \\ * Correspondence: barbara.onida@polito.it; Tel.: +39-011-090-4631 \\ + These authors contributed equally to this work.
}

Received: 14 February 2019; Accepted: 2 March 2019; Published: 11 March 2019

\begin{abstract}
The physico-chemical and biological properties of nanostructured $\mathrm{ZnO}$ are combined with the non-toxic and eco-friendly features of the $\mathrm{scCO}_{2}$-mediated drug loading technique to develop a multifunctional antimicrobial drug delivery system for potential applications in wound healing. Two nanostructured $\mathrm{ZnO}(\mathrm{NsZnO})$ with different morphologies were prepared through wet organic-solvent-free processes and characterized by means of powder X-ray diffraction, field emission scanning electron microscopy (FESEM), and nitrogen adsorption analysis. The antimicrobial activity of the two samples against different microbial strains was investigated together with the in vitro $\mathrm{Zn}^{2+}$ release. The results indicated that the two $\mathrm{ZnO}$ nanostructures exhibited the following activity: S. aureus $>$ C. albicans $>$ K. pneumoniae. A correlation between the antimicrobial activity, the physico-chemical properties (specific surface area and crystal size) and the $\mathrm{Zn}^{2+}$ ion release was found. Ibuprofen was, for the first time, loaded on the NsZnO carriers with a supercritical $\mathrm{CO}_{2}$-mediated drug impregnation process and in vitro dissolution studies of the loaded drug were performed. A successful loading up to $14 \% w / w$ of ibuprofen in its amorphous form was obtained. A preliminary drug release test showed that up to $68 \%$ of the loaded ibuprofen could be delivered to a biological medium, confirming the feasibility of using $\mathrm{NsZnO}$ as a multifunctional antimicrobial drug carrier.
\end{abstract}

Keywords: Supercritical $\mathrm{CO}_{2}$; ibuprofen; $\mathrm{NsZnO;} \mathrm{antimicrobial} \mathrm{activity}$

\section{Introduction}

Zinc oxide $(\mathrm{ZnO})$ is a multifunctional material possessing unique physical and chemical properties, such as high chemical stability, a high electrochemical coupling coefficient, a broad range of radiation absorption and high photostability [1]. For these reasons it is largely used in many applications, ranging from electronics, optoelectronics, sensors and photocatalysis [2,3].

$\mathrm{ZnO}$ is also widely used in topical formulations to address several skin conditions, like burns, scars, and irritations, thanks to its non-toxicity, biocompatibility and antimicrobial activity [4]. 
$\mathrm{ZnO}$ exhibits three crystal structures named wurtzite, zinc-blend, and an occasionally noticed rock-salt [5], which allow it to be employed as a nanostructured material for different nanotechnology applications in many industrial areas, such as gas sensors, biosensors, semiconductors, piezoelectric devices, field emission displays and photocatalytic degradation of pollutants [6].

Due to the wide spread of nanotechnology, cosmetics and pharmaceuticals have also been revolutionized. Among all the materials, $\mathrm{ZnO}$ has been developed in different nanostructures to enhance its interaction with the skin and to improve the existing products. A promising application consists of the addition of $\mathrm{ZnO}$ in wound dressing materials. Nanocomposites represent a good example [7]: they consist of the addition of $\mathrm{ZnO}$ nanostructures to polymeric matrices [8-11] in order to impart novel functionalities, such as antibacterial activity. It is well-established in the literature that $\mathrm{ZnO}$ displays significant bactericidal properties over a broad range of bacteria $[12,13]$. This occurs due to several mechanisms, such as generation of reactive oxygen species (ROS), zinc ion release, membrane dysfunction, and nanoparticle penetration. Moreover the physico-chemical parameters of the nanomaterial, such as size, morphology, and specific surface area, remarkably affect the antibacterial properties of $\mathrm{ZnO}[14,15]$. It has also been demonstrated that zinc ion release can improve wound healing [16,17], since zinc is an essential trace element in the human body and acts as a cofactor in zinc-dependent matrix metalloproteinases that augment auto debridement and keratinocyte migration during wound repair.

The treatment of painful wounds is another important issue in biomedicine. It has been demonstrated that painful wounds can take more time to heal, leading to a lack of compliance by the patients. Several research works [18] have addressed the development of innovative wound dressings, able to deliver small doses of anti-inflammatory analgesic drugs to the wound [19]. In this context the use of $\mathrm{ZnO}$ as a drug carrier to be included in the wound dressing device could be of particular interest thanks to its outstanding biocompatibility, even though the application of this material as a drug delivery system has not been investigated widely in the literature [20] and may be considered at its nascent stage.

The use of organic solvents in pharmaceutical technologies is another challenging issue since it leads both to health concerns, which are related to the toxicity of residual solvents in the final products, and to a negative environmental impact. In the last decade, supercritical fluid technology has been emerging as a green drug impregnation method [21]. Supercritical carbon dioxide $\left(\mathrm{scCO}_{2}\right)$ is the most used supercritical solvent because it is readily available, cheap, non-toxic, non-flammable, and recyclable. At the end of the $\mathrm{scCO}_{2}$-mediated drug impregnation process a simple depressurization step allows a ready-to-use organic-solvent-free drug loaded material to be obtained. Furthermore, it offers the possibility to tailor the operating parameters of the impregnation process, such as temperature, pressure, and time, on the basis of the selected drug/carrier system [22]. This permits a better drug/carrier interaction to be obtained, with the drug in an amorphous state, which improves its dissolution profile and, consequently, its bioavailability [23].

Notwithstanding the above reported remarkable advantages, some drawbacks in the use of this technology have emerged, such as the scarce ability of $\mathrm{scCO}_{2}$ to dissolve polar and ionic species, since it is a linear molecule with no net dipole moment. Furthermore, the elevated pressure required and high maintenance cost can represent a limitation in the use of this technology [21].

Even though the incorporation of active pharmaceutical ingredients (APIs) in organic and inorganic carriers through $\mathrm{scCO}_{2}$ has been proposed in different research areas [22,24,25], the loading of drugs on $\mathrm{ZnO}$ carriers has not been investigated yet [23] and, to the best of our knowledge, the clotrimazole incorporation described in our previous work [26] represents the very first study about the loading of an API on nanostructured $\mathrm{ZnO}$ by means of $\mathrm{scCO}_{2}$.

The fundamental idea of this research project is to combine the physico-chemical and biological properties of $\mathrm{ZnO}$ with the eco-friendly features of the $\mathrm{scCO}_{2}$-mediated drug impregnation process to develop a green multifunctional device for treating painful wounds. This consists of the combination of antibacterial and anti-inflammatory/analgesic action in a single delivery system. $\mathrm{ZnO}$ is particularly 
suitable for this role, because its nanostructure can be tailored to host drug molecules and because it can offer intrinsic antimicrobial activity [15]. Ibuprofen (IBU) has been selected as the drug to be hosted in the $\mathrm{ZnO}$ nanostructures, since it is one of the most commonly used and most frequently prescribed non-steroidal anti-inflammatory drug (NSAID) for oral and topical administration due to its prominent analgesic role $[27,28]$, and it has already been employed to prepare innovative pain-reducing wound dressings $[18,19]$. Furthermore IBU has also been widely used in many $\mathrm{scCO}_{2}-$ mediated drug impregnation processes [23].

This work is a feasibility study aiming at investigating the possibility of loading IBU on different $\mathrm{ZnO}$ carriers by means of $\mathrm{scCO}_{2}$ and checking the antimicrobial activity as well as the capability of the obtained system to release $\mathrm{Zn}^{2+}$ ions and the drug, which are essential requirements for the development of a multifunctional device for wound healing applications. Two nanostructured $\mathrm{ZnO}$ (NsZnO) powders with different morphologies and physico-chemical parameters were synthetized through wet organic-solvent-free processes [26] and characterized by means of powder X-ray diffraction, FESEM images, and nitrogen adsorption analysis. The samples were also characterized from a biological point of view; particularly, their antimicrobial activity against different microbial strains and the in vitro $\mathrm{Zn}^{2+}$ release profiles from the $\mathrm{NsZnO}$ matrices were evaluated. IBU was loaded on the $\mathrm{NsZnO}$ carriers with a $\mathrm{scCO}_{2}-$ mediated drug impregnation process and in vitro dissolution studies of the loaded drug were performed.

\section{Materials and Methods}

\subsection{Materials}

All the reagents for chemical synthesis, as well as ibuprofen, were purchased from Sigma-Aldrich and used as received without further purification. Carbon dioxide with a purity of $99.998 \%$ was supplied by SIAD (Italy). Bidistilled water was used throughout this study.

\subsection{Synthesis of Nanostructured $\mathrm{ZnO}(\mathrm{NsZnO})$}

Two different NsZnO materials were synthesized as previously described [26], using two different organic solvent free processes: the first one was based on the use of sole water as the solvent, i.e., a chemical bath deposition (NsZnO-1) method, while the second was a soft-template sol-gel synthesis method (NsZnO-2).

\subsection{Drug Adsorption from Supercritical Carbon Dioxide}

The $\mathrm{scCO}_{2}-$ mediated drug loading was carried out using a procedure that had been developed in previous works [26,29]. It consisted of contacting the drug and each of the two NsZnO materials in a static atmosphere of $\mathrm{scCO}_{2}$ at constant temperature and pressure (Figure 1). First, a pellet of the drug $(100 \mathrm{mg})$ and a pellet of the $\mathrm{NsZnO}(100 \mathrm{mg})$ were prepared and introduced into a glass cylinder of $1 \mathrm{~cm}$ diameter. A disc of filter paper was placed between the two pellets to prevent their contact and guarantee an efficient recovery of the samples at the end of the drug loading process. The glass cylinder was placed inside a stainless-steel vessel, which was put in an oven that kept the entire system at constant temperature. Liquid $\mathrm{CO}_{2}$ was used to fill the vessel, then the temperature was increased to $35^{\circ} \mathrm{C}$ and additional $\mathrm{CO}_{2}$ was pumped to reach the target pressure (10 MPa). The pump was coupled with a cryogenic bath to prevent cavitation. The system was maintained at the above-reported conditions for $12 \mathrm{~h}$. At the end of the drug loading process, the on-off valve was opened, and the apparatus was brought back to atmospheric pressure by means of a heated restrictor valve.

The IBU-containing materials are denoted hereafter as IBU@NsZnO-1 and IBU@NsZnO-2.

Moreover, the two carriers as such were treated in the same conditions in the absence of IBU in the glass cylinder, in order to investigate the effect of the $\mathrm{scCO}_{2}$ treatment on the NsZnO samples. 


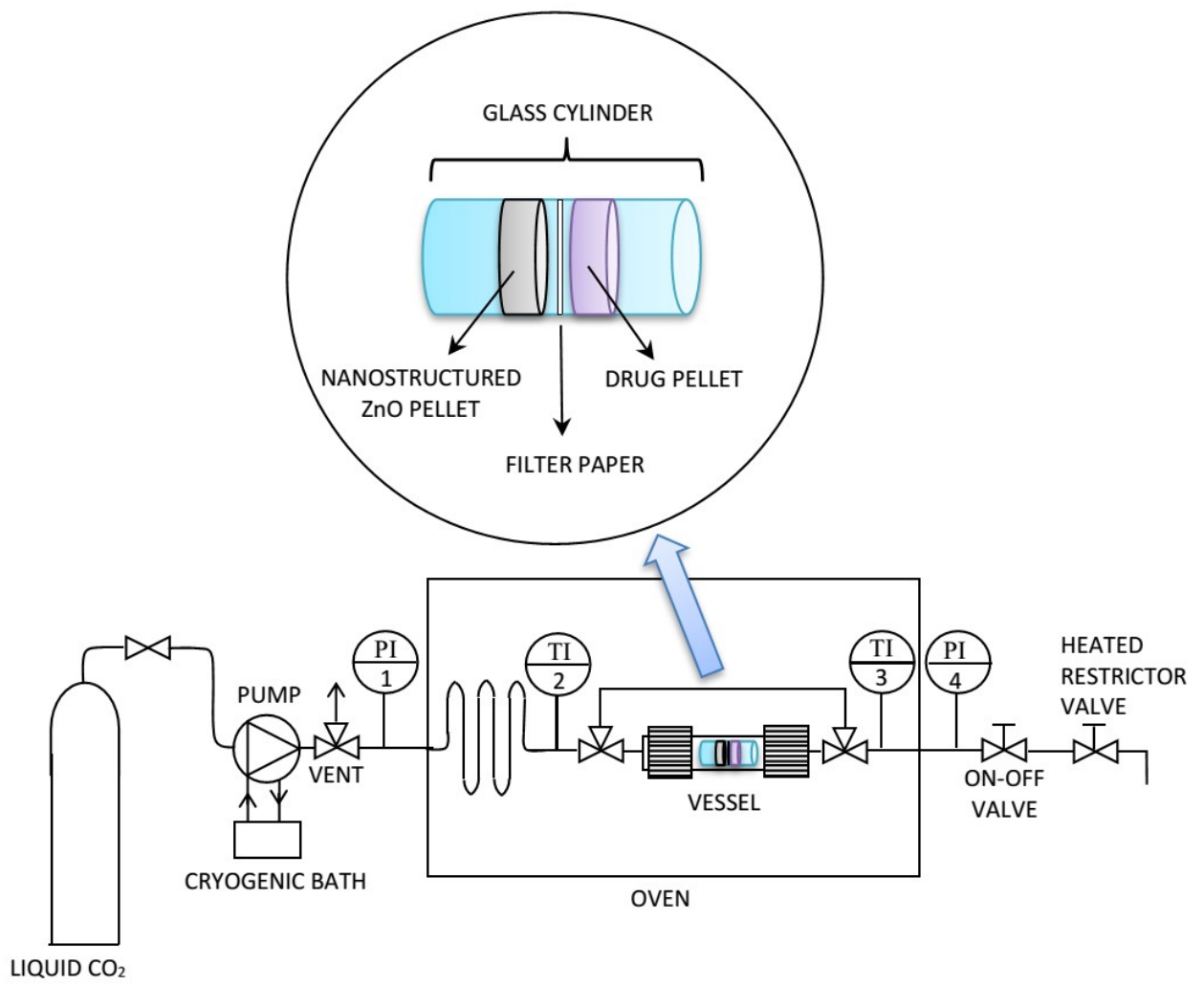

Figure 1. Experimental apparatus for supercritical carbon dioxide $\left(\mathrm{scCO}_{2}\right)$-mediated drug loading.

\subsection{Morphological Characterization}

FESEM images were recorded with an FESEM Zeiss Merlin instrument, equipped with an EDS detector (Oxford Instruments, Abingdon-on-Thames, UK).

\subsection{Powder X-ray Diffractometry}

XRD patterns were obtained using a Panalytical X'Pert ( $\mathrm{Cu}$ K $\alpha$ radiation, Almelo, The Netherlands) diffractometer. Data were collected with a 2D solid state detector (PIXcel) from 20 to $702 \theta$ with a step size of $0.0012 \theta$ and a wavelength of $1.54187 \AA$.

\subsection{Nitrogen Adsorption Analysis}

Nitrogen adsorption isotherms were measured using a Quantachrome AUTOSORB-1 instrument (Boynton Beach, FL, USA). Before the adsorption measurements, samples were outgassed for $2 \mathrm{~h}$ at $100{ }^{\circ} \mathrm{C}$. BET specific surface areas $\left(\mathrm{SSA}_{\mathrm{BET}}\right)$ were calculated in the relative pressure range of 0.04-0.1.

\subsection{Thermogravimetry Analysis}

Thermogravimetry (TG) analyses were carried out between $20{ }^{\circ} \mathrm{C}$ and $800{ }^{\circ} \mathrm{C}$ in air (flow rate $100 \mathrm{~mL} / \mathrm{min}$ with a heating rate of $10^{\circ} \mathrm{C} / \mathrm{min}$ ) using a SETARAM 92 instrument (Caluire et Cuire, France).

\subsection{Antimicrobial Activity of $\mathrm{NsZnO}$}

\subsubsection{Microbial Strains and Culture Conditions}

The antibacterial activity of NsZnO-1 and NsZnO-2 was tested against a Gram-positive and a Gram-negative bacterial strain, such as Staphylococcus aureus ATCC 29213 and Klebsiella pneumoniae ATCC 700603, respectively. The antifungal activity of NsZnO-1 and NsZnO-2 samples was investigated against Candida albicans ATCC 90023. The strains were purchased from American Type Culture Collection (ATCC) (Manassas, VA, USA). 


\subsubsection{Inocula Preparation}

Microorganism inocula were prepared by picking two to three colonies from an overnight culture of S. aureus/K. pneumoniae on Brain heart infusion agar (BHA, Merck KGaA, Darmstadt, Germany) or of C. albicans on Sabouraud dextrose (SAB, Merck KGaA, Darmstadt, Germany) agar at $37^{\circ} \mathrm{C}$ (bacteria) or $35{ }^{\circ} \mathrm{C}$ (yeasts), suspending them in $5 \mathrm{~mL}$ of $0.85 \%$ normal saline, to yield a 0.5 McFarland turbidity standard, corresponding to a suspension of $\sim 5 \times 10^{8} \mathrm{CFU} / \mathrm{mL}$ for bacteria or $5 \times 10^{6} \mathrm{CFU} / \mathrm{mL}$ for yeasts.

Bacterial suspensions were diluted 1:1000 in Mueller Hinton broth (MHB, Merck KGaA, Darmstadt, Germany) to obtain a final concentration of $10^{5} \mathrm{CFU} / \mathrm{mL}$. Fungal suspension was diluted 1:1000 in RPMI-1640 without sodium bicarbonate and with L-glutamine (Invitrogen, San Giuliano Milanese, Milano, Italy), buffered to pH 7.0 with $0.165 \mathrm{M}$ morpholinepropanesulfonic acid (MOPS) (Sigma-Aldrich, Milan, Italy), and supplemented with glucose $0.2 \%$, to obtain a concentration of $10^{3} \mathrm{CFU} / \mathrm{mL}$. Inocula were confirmed by colony counts in duplicate.

\subsubsection{In Vitro Antimicrobial Assays}

Determination of Minimum inhibitory concentration (MIC), Minimum bactericidal concentration (MBC), and Minimum fungicidal concentration (MFC).

The antimicrobial activity of NsZnO-1 and NsZnO-2 was determined using a broth microdilution (BM) method susceptibility assay, according to Clinical and Laboratory Standard Institute guidelines (CLSI document M07-A9 for bacteria, and M27-A3 for yeasts) [30,31]. As guidelines were not available for susceptibility testing of $\mathrm{NsZnO}$, the antimicrobial activity was assessed following the CLSI BM method, with some modifications.

MIC determination was performed by serial dilution using 96-well microtiter plates (Sarstedt, Milan, Italy). Stock suspensions of NsZnO prepared at 30,000 $\mu \mathrm{g} / \mathrm{mL}(w / v)$ in phosphate buffered solution (PBS; pH 7.4) were dispersed for $1 \mathrm{~h}$ using an ultrasonic bath, in order to minimize sedimentation of NsZnO particles. Doubling dilutions of the $\mathrm{ZnO}$ ranging from 15,000 to $30 \mu \mathrm{g} / \mathrm{mL}$ were prepared in 96-well microtiter plates in MHB for bacteria or in RPMI-1640 with MOPS for yeasts. After inoculum addition $(0.1 \mathrm{~mL})$, the plates were incubated under normal atmospheric conditions at $37^{\circ} \mathrm{C}$ (bacteria) or $35^{\circ} \mathrm{C}$ (yeasts) for $24 \mathrm{~h}$. A sterile medium incubated under the same conditions was used as a blank, while the medium inoculated with the target microorganisms (without NsZnO) was used as a positive control of growth. All determinations were performed in duplicate. The lowest concentration of the NsZnO showing complete inhibition of visible growth was defined as MIC.

MBC and MFC of NsZnO were determined by subculturing $10 \mu \mathrm{L}$ of broth taken from all the wells without visible growth onto BHA (bacteria) or SAB (yeasts) agar plates that did not contain the test agents. After incubation for $24 \mathrm{~h}$ at $37^{\circ} \mathrm{C}$ (bacteria) or $35^{\circ} \mathrm{C}$ (yeasts), MBC or MFC were defined as the lowest concentration of $\mathrm{ZnO}$ resulting in the death of $99.9 \%$ of the inoculum in no subculture [32].

\section{Viable microorganism counts}

To assess the antimicrobial activity of NsZO over time, the number of viable microorganisms was measured by monitoring bacterial/fungal growth after $24 \mathrm{~h} \mathrm{[33].}$

Briefly, the bacterial or yeast cells were grown overnight in BHI (Merck KGaA) or Sabouraud Dextrose (SAB, Merck KGaA, Darmstadt, Germany) broth at $37^{\circ} \mathrm{C}$ or $35^{\circ} \mathrm{C}$, respectively. Bacteria and/or yeasts were harvested by centrifugation, washed, suspended in PBS, and diluted to yield a stock suspension of $\sim 5 \times 10^{5} \mathrm{CFU} / \mathrm{mL}$. All the NsZnO samples with concentration of 15,000 $\mu \mathrm{g} / \mathrm{mL}$, suspended in PBS, were incubated with bacterial or yeast suspension in a shaker incubator at $37^{\circ} \mathrm{C}$ or $35{ }^{\circ} \mathrm{C}$, respectively, for $24 \mathrm{~h}$. PBS solution was used as a negative control. All samples were serially diluted and $100 \mu \mathrm{L}$ of bacterial/yeasts suspension was drawn from each sample tube, spread on BHA or SAB agar plates, and incubated at $37^{\circ} \mathrm{C}$ or $35^{\circ} \mathrm{C}$ for $24 \mathrm{~h}$, so that the number of $\mathrm{CFU} / \mathrm{mL}$ could be determined. 


\subsection{In Vitro Zinc Ions Release}

Zinc ion release from the samples NsZnO-1 and NsZnO-2 was studied using vertical Franz diffusion cells and synthetic skin (Dow Corning, 7-4107, Silicone Elastomer Membrane, Biesterfeld Polychem, Milan, Italy). Suspensions of NsZnO (5 mg of powder in $0.5 \mathrm{~mL}$ of PBS buffer solution) were employed as the donor phases. The receiving phase consisted of a PBS buffer solution at pH 7.4. The apparatus was maintained under stirring at $33{ }^{\circ} \mathrm{C}$, during which, at scheduled time intervals, the receiving phase was withdrawn and entirely substituted with a fresh receiving phase. Zinc ion quantification was performed in each withdrawn sample using inductively coupled plasma mass spectrometry (ICP-MS, Thermo Scientific, Waltham, MA, USA).

\subsection{Preliminary In Vitro Drug Release Study}

The ability of the IBU-loaded NsZnO to release IBU was tested by using a multicompartment rotating cell equipped with a hydrophilic dialysis membrane (Spectra/Por, Spectrum ${ }^{\circledR}$, cut-off 12,000-1,4000 Da, Sigma-Aldrich, Milan, Italy). PBS solution (1 mL) was used as the receiving medium. At predetermined time intervals, the receiving phase was completely replaced by a fresh solution, and analyzed for IBU content at 263 nm, using a Beckman-Coulter DU 730 Spectrophotometer (Indianapolis, IN, USA).

\section{Results and Discussion}

Figure 2 shows the FESEM pictures of NsZnO-1 and NsZnO-2. As observed in the previous study [26], the two carriers were characterized by different morphologies.

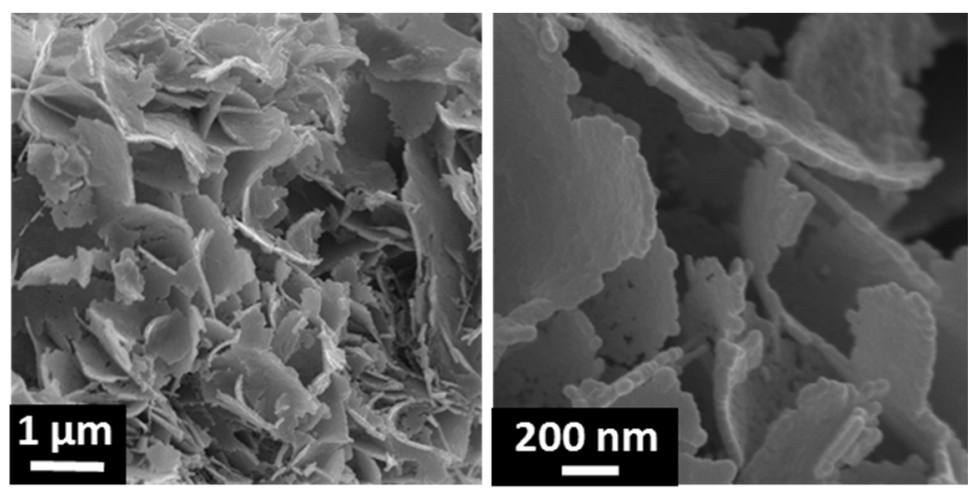

(a)

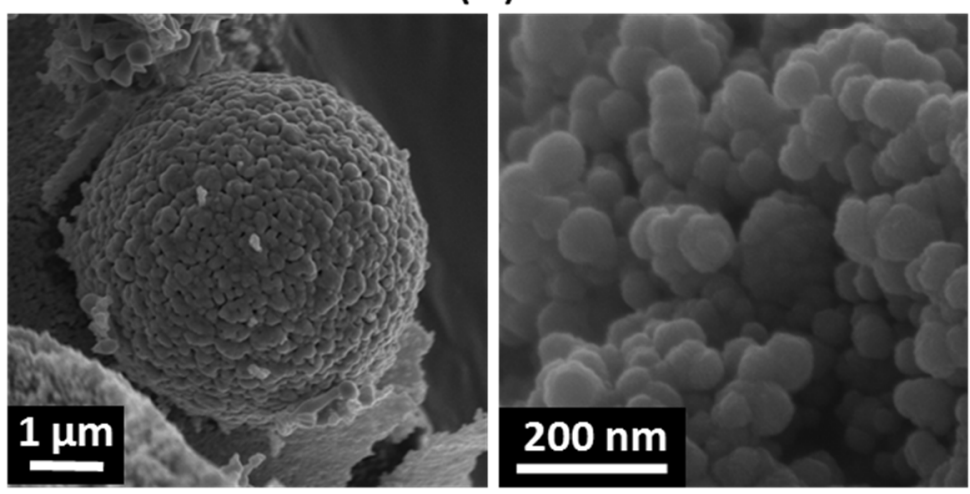

(b)

Figure 2. FESEM images of nanostructured (Ns)ZnO-1 (a) and NsZnO-2 (b). 
NsZnO-1 appeared in the form of aggregates of nanosheets, with a thickness of about $20 \mathrm{~nm}$, that were formed by the self-assembling of ovoid nanoparticles (having sizes around 15-20 nm). This morphology is in agreement with the mechanism growth proposed by Kakiuchi et al. [34].

The morphology of NsZnO-2 consisted of micrometric and sub-micrometric aggregates of nanoparticles with heterogeneous sizes of tens of nanometers.

Primary nanoparticles of NsZnO-1 were definitely smaller than those of NsZnO-2. The values of BET specific surface area and pore volume obtained by nitrogen adsorption are shown in Table 1. As previously observed [26], both features were larger for NsZnO-1 $\left(68 \mathrm{~m}^{2} / \mathrm{g}\right.$ and $0.230 \mathrm{~cm}^{3} / \mathrm{g}$, respectively) than for NsZnO-2 $\left(12 \mathrm{~m}^{2} / \mathrm{g}\right.$ and $0.050 \mathrm{~cm}^{3} / \mathrm{g}$, respectively), due to the lower particles size of NsZnO-1.

Table 1. Specific surface area (SSA) and pore volume values before and after the ibuprofen (IBU) adsorption by $\mathrm{scCO}_{2}$ process.

\begin{tabular}{ccccc}
\hline & \multicolumn{2}{c}{ Before IBU Adsorption } & \multicolumn{2}{c}{ After IBU Adsorption } \\
\cline { 2 - 5 } & $\mathbf{S S A}_{\text {BET }}\left(\mathbf{m}^{2} / \mathbf{g}\right)$ & Pore Volume $\left(\mathbf{c m}^{3} / \mathbf{g}\right)$ & $\mathbf{S S A}_{\text {BET }}\left(\mathbf{m}^{2} / \mathbf{g}\right)$ & Pore Volume $\left(\mathrm{cm}^{3} / \mathbf{g}\right)$ \\
\hline NsZnO-1 & 68 & 0.230 & 8 & 0.04 \\
NsZnO-2 & 12 & 0.050 & nil & nil \\
\hline
\end{tabular}

Figure 3 reports the XRD patterns of both NsZnO materials, which reveal the occurrence of a highly crystalline single hexagonal phase of a wurtzite structure (JCPDS ICDD 36-1451). Comparing the XRD patterns of the two samples, it is evident that NsZnO-1 showed broader peaks than NsZnO-2, in agreement with the smaller particles size evidenced by FESEM analyses.

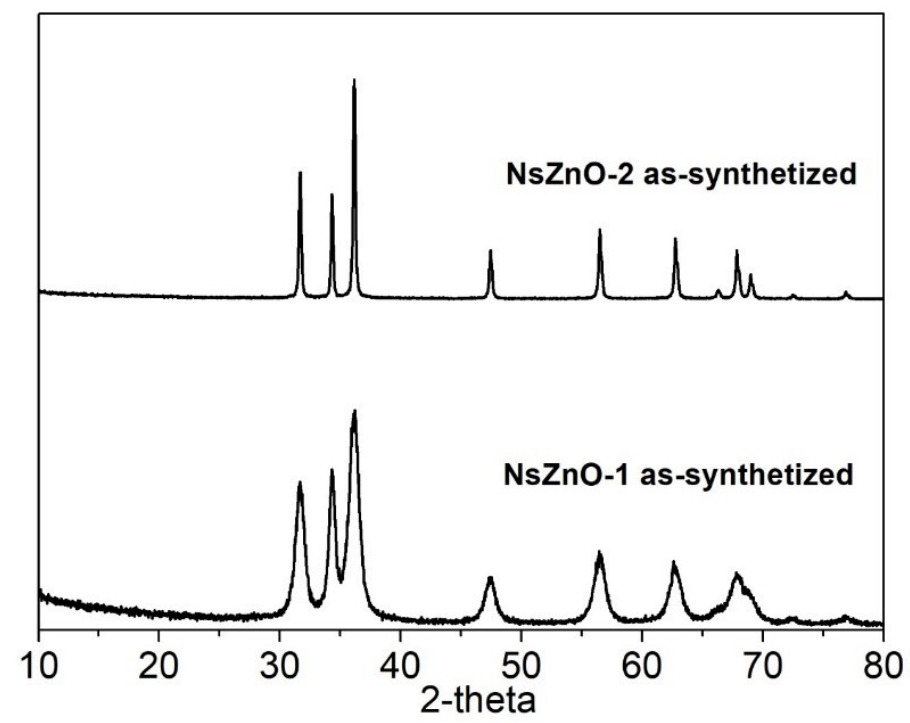

Figure 3. XRD patterns of NsZnO-1 and NsZnO-2.

In order to investigate the stability of $\mathrm{NsZnO}$ carriers in $\mathrm{scCO}_{2}$, the $\mathrm{XRD}$ patterns of $\mathrm{NsZnO}-1$ and NsZnO-2 after treatment in $\mathrm{scCO}_{2}$ for $12 \mathrm{~h}$, at $35^{\circ} \mathrm{C}$ and $10 \mathrm{MPa}$, were collected and these are reported in Figure 4. In both cases the hexagonal wurtzite pattern of $\mathrm{ZnO}$ was preserved, and no new peaks were detected. This result showed that no extensive reaction between $\mathrm{ZnO}$ and the $\mathrm{CO}_{2}$ occurred, which should not have been taken for granted, considering that the reaction between $\mathrm{ZnO}$ and $\mathrm{CO}_{2}$ to give $\mathrm{ZnCO}_{3}$ is a well-known phenomenon $[35,36]$. This evidence confirms the feasibility of using $\mathrm{scCO}_{2}$ as a solvent for the drug loading of $\mathrm{NsZnO}$ carriers. 


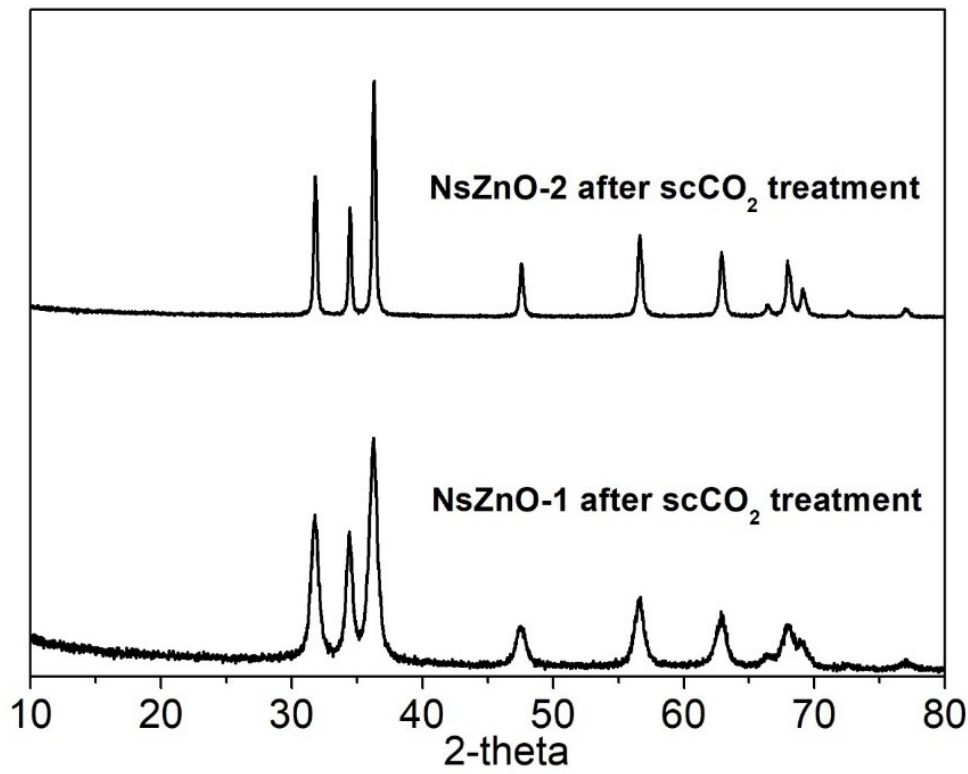

Figure 4. XRD patterns of NsZnO-1 and NsZnO-2 after $\mathrm{scCO}_{2}$ treatment.

As far as the IBU loading is concerned, its content was calculated as the weight loss by TG analysis (Figure S1) and was found equal to 14\% w/w for IBU@NsZnO-1 and 9\% w/w for IBU@NsZnO-2, respectively (Table 2).

Table 2. Ibuprofen content in IBU@NsZnO-1 and IBU@NsZnO-2.

\begin{tabular}{cc}
\hline & IBU Content $(\%$ w/w) \\
\hline IBU@NsZnO-1 & 14 \\
IBU@NsZnO-2 & 9 \\
\hline
\end{tabular}

The larger IBU content in IBU@NsZnO-1 than in IBU@NsZnO-2 was ascribed to the larger specific surface area and pore volume of NsZnO-1, which yielded larger drug adsorption and loading capacity.

Due to the presence of IBU molecules on the NsZnO carriers, the specific surface area and pore volume drastically decreased in both systems, as revealed by the data reported in Table 1.

It is worth noting that IBU contents in the two systems were similar to those previously obtained for clotrimazole adsorbed by $\mathrm{scCO}_{2}$ on $\mathrm{NsZnO}-1$ and $\mathrm{NsZnO}-2$ carriers [26], which were equal to $17 \%$ $w / w$ and $14 \% w / w$, respectively. This suggests the robustness of the $\mathrm{scCO}_{2}$ approach in the drug loading of NsZnOs.

XRD analyses were carried out to characterize IBU@NsZnO-1 and IBU@NsZnO-2. Figure 5 reports the XRD patterns of both systems, in comparison with those of the materials as-such and the pure crystalline IBU. No additional diffraction peaks typical of the crystalline IBU were observed for either IBU@NsZnO-1 or IBU@NsZnO-2 samples. This reveals that drug molecules are not assembled in the crystalline form on the two carriers.

The same result was previously obtained in the case of clotrimazole [26]. The amorphous form of the drug adsorbed on $\mathrm{NsZnO}$ from $\mathrm{scCO}_{2}$ may be ascribed to the $\mathrm{scCO}_{2}$-mediated process, which is known to favor the amorphization of the adsorbed drug [23]. This is a crucial aspect, in particular for poorly water-soluble drugs, because it is widely accepted that amorphization of the drug molecules plays a key role in increasing their dissolution rate and solubility. 


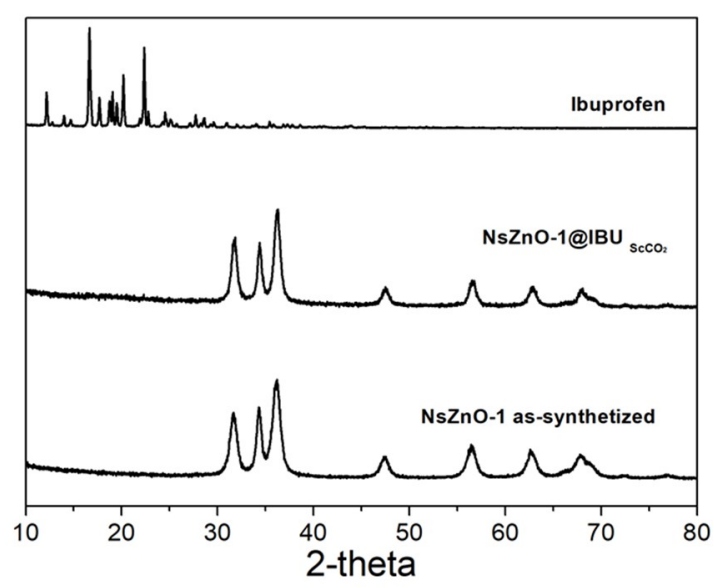

(a)

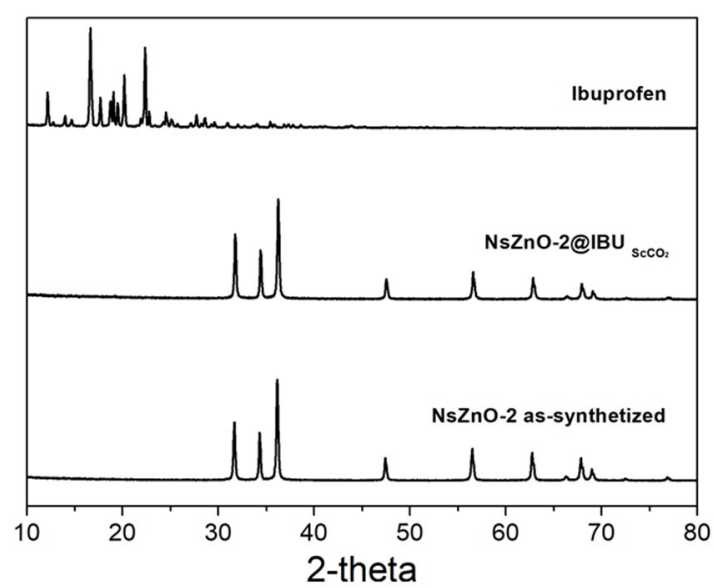

(b)

Figure 5. (a) XRD patterns of NsZnO-1, IBU@NsZnO-1, and pure crystalline IBU. (b) XRD patterns of NsZnO-2, IBU@NsZnO-2, and pure crystalline IBU.

In order to investigate the antimicrobial activity of NsZnOs, some microbiological parameters, such as MIC, MBC, and MFC were used (Table 3). In addition, a CFU assay was used to measure the antimicrobial activity of the NsZnOs over time by monitoring bacterial/fungal growth within $24 \mathrm{~h}$ (Table 4, and Figure 6).

Table 3. Minimum inhibitory concentration (MIC), and minimum bactericidal concentration (MBC), of NsZnO-1 and NsZnO-2 determined for S. aureus, K. pneumoniae, and C. albicans expressed in $\mu \mathrm{g} / \mathrm{mL}$. Minimum fungicidal concentration (MFC) for C. albicans was not determined.

\begin{tabular}{cccccc}
\hline Microbial Strain & \multicolumn{2}{c}{ S. aureus } & \multicolumn{2}{c}{ K. pneumoniae } & C. albicans \\
\hline & MIC $(\mu \mathrm{g} / \mathrm{mL})$ & MBC $(\mu \mathrm{g} / \mathrm{mL})$ & MIC $(\mu \mathrm{g} / \mathrm{mL})$ & MBC $(\mu \mathrm{g} / \mathrm{mL})$ & $\mathrm{MIC}(\mu \mathrm{g} / \mathrm{mL})$ \\
\hline NsZnO-1 & 120 & $>470$ & 470 & 1875 & $>15,000$ \\
NsZnO-2 & 230 & $>470$ & 930 & $>3750$ & $>15,000$ \\
\hline
\end{tabular}

As emerged from data shown in Table 3 the two $\mathrm{ZnO}$ nanostructures exhibited a stronger activity on the Gram-positive S. aureus than the Gram-negative K. pneumoniae. Between the two $\mathrm{ZnO}$ nanostructures, NsZnO-1 showed better activity than NsZnO-2 against S. aureus with an MIC value of $120 \mu \mathrm{g} / \mathrm{mL}$ vs $230 \mu \mathrm{g} / \mathrm{mL}$. Since $\mathrm{ZnO}$ suspensions appeared "cloudy" in the case of C. albicans, it was not possible to determine the MIC from the visual appearance of the medium; hence, MFC was not assessed for this yeast (data not shown). In general, MBCs were two concentrations higher than MICs, with exception of NsZnO-2 that showed a MBC value one concentration higher than MIC against $S$. aureus, suggesting a more bacteriostatic activity of these compounds.

Table 4 and Figure 6 report the results of the viable microorganism counts assessed through a CFU assay. The bactericidal activity of $\mathrm{NsZnO}-1$ against $S$. aureus (expressed in $\mathrm{Log} \mathrm{CFU} / \mathrm{mL}$ ) was greater than that achieved by NsZnO-2 (1 vs 4.22, Figure 6a). The same trend, even if with less microbial load reduction values, is evident in Figure $6 \mathrm{~b}$ for K. pneumoniae, where the $\mathrm{Log} \mathrm{CFU} / \mathrm{mL}$ of bacterial load was 7.21 and 8.42 for NsZnO-1 and NsZnO-2, respectively. Despite the failure of the broth dilution technique for yeasts, the enumeration of viable organisms' method was efficient in the determination of the antifungal activity. The results are shown in Figure 6c. NsZnO-1 log counts observed for C. albicans was 5.27, whereas NsZnO-2 was able to reduce the yeast cells growth of $6.15 \mathrm{log}$ in comparison with $\mathrm{ZnO}$-free controls (7.02 log). Taken together, these results indicate that the two $\mathrm{ZnO}$ nanostructures exhibited a better activity towards S. aureus than K. pneumoniae and C. albicans. 
Table 4. Comparison of antibacterial/antifungal activity of NsZnO-1 and NsZnO-2 against S. aureus, K. pneumoniae, and C. albicans determined with the enumeration of viable microorganism assay and expressed in $\mathrm{CFU} / \mathrm{mL}$ after $24 \mathrm{~h}$ of incubation.

\begin{tabular}{cccc}
\hline Microbial Strain & S. aureus & K. pneumoniae & C. albicans \\
\hline NsZnO-1 & $10 \mathrm{CFU} / \mathrm{mL}$ & $1.62 \times 10^{7} \mathrm{CFU} / \mathrm{mL}$ & $1.85 \times 10^{5} \mathrm{CFU} / \mathrm{mL}$ \\
$\mathrm{NsZnO}-2$ & $1.65 \times 10^{4} \mathrm{CFU} / \mathrm{mL}$ & $2.66 \times 10^{8} \mathrm{CFU} / \mathrm{mL}$ & $1.43 \times 10^{6} \mathrm{CFU} / \mathrm{mL}$ \\
\hline
\end{tabular}

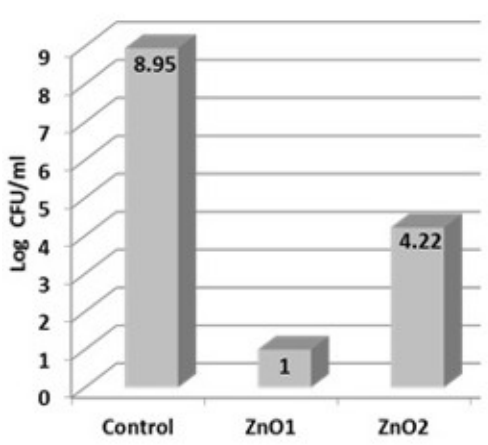

S. aureus

(a)

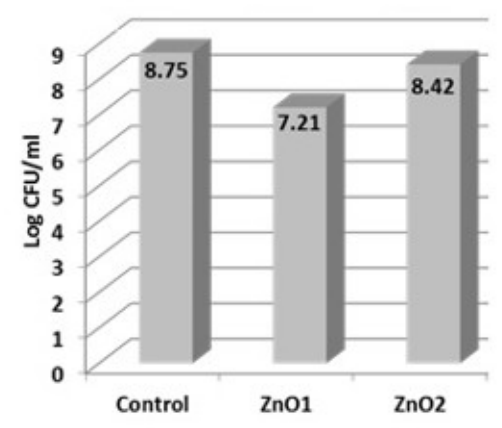

K. pneumoniae

(b)

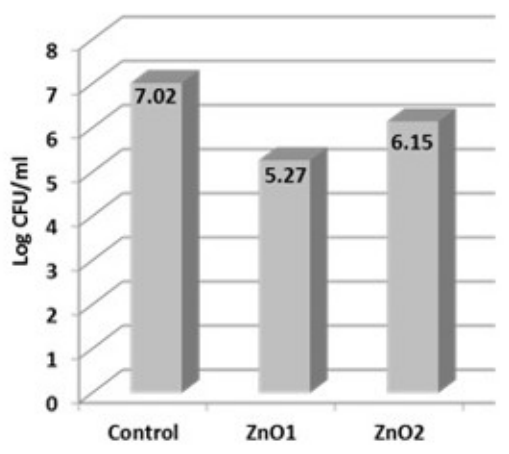

C.albicans

(c)

Figure 6. Comparison of antibacterial activities of NsZnO-1 and NsZnO-2 against S. aureus (a), K. pneumoniae (b), and C. albicans (c) expressed in $\mathrm{Log} \mathrm{CFU} / \mathrm{mL}$.

Our data are difficult to compare due to the different methods and microorganisms used in the antimicrobial activity determination. However, these data are in agreement with those of some authors who detected a better antimicrobial activity of $\mathrm{ZnO}$-compounds on Gram positive than Gram negative bacteria, and a good antifungal activity on C. albicans $[13,37,38]$.

In addition, our results agree with the conclusions of Reddy et al. [39] and Tayel et al. [40] and disagree with the conclusions of Pasquet et al. [14]. In detail, Reddy and Tayel explained that the peptidoglycan cell-wall of Gram-positive bacteria may promote $\mathrm{ZnO}$ attachment onto the cell wall, whereas cell-wall lipophilic components of Gram-negative bacteria may oppose this attachment. Until now, the antifungal activity mechanism has not been well clarified; however, the candidacidal mechanism of $\mathrm{ZnO}$ can be probably ascribed to the cellular structure disruption or to inhibition of biological molecular synthesis due to $\mathrm{Zn}^{2+}$ release [38].

Among the NsZnOs investigated, the sample NsZnO-1 showed higher antimicrobial activity compared to NsZnO-2. This trend was confirmed by both the in vitro tests. This phenomenon could be ascribed to the crystallite sizes of the nanoparticles, which have been reported to greatly impact their antimicrobial activity, probably because of a greater accumulation of the nanoparticles inside the cell membrane and cytoplasm [12]. In fact, NsZnO-1 is characterized by lower crystallite sizes than NsZnO-2. This observation can be reinforced by the results obtained with C. albicans, against which NsZnO-1 showed better antifungal activity than NsZnO-2. These conclusions are consistent with the study of Lipovsky et al. [41], who suggested that $\mathrm{ZnO}$ nanoparticles display a marked activity against C. albicans and that the cytotoxic effect is size dependent.

Among the key mechanisms influencing the antimicrobial activity of nanostructured $\mathrm{ZnO}$, it is important to consider the release of $\mathrm{Zn}^{2+}$ ions.

For this reason, a simple test was carried out to study the zinc ion release from NsZnO-1 and NsZnO-2 using vertical Franz diffusion cells equipped with synthetic skin. The results drawn from the zinc ion quantification are shown in Figure 7. The in vitro $\mathrm{Zn}^{2+}$ release study evidenced the ability of both the NsZnOs to release $\mathrm{Zn}^{2+}$, highlighting their potential use as multifunctional antimicrobial drug carriers. 


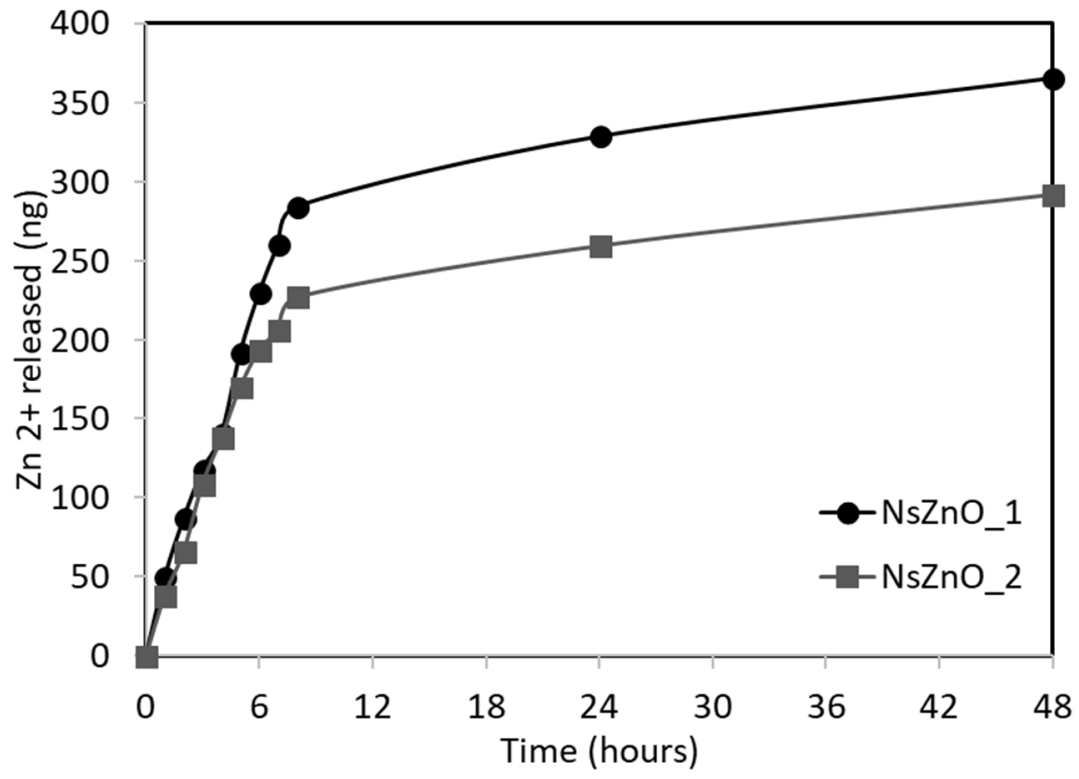

Figure 7. In vitro $\mathrm{Zn}^{2+}$ release from $\mathrm{NsZnO}-1$ and $\mathrm{NsZnO}-2$.

A higher amount of $\mathrm{Zn}^{2+}$ ion was released from NsZnO-1 and this was ascribed to the lower crystallite size and the higher SSA of the sample. The maximum amount of released $\mathrm{Zn}^{2+}$ ion after $48 \mathrm{~h}$ corresponded to a percentage by mass of zinc equal to about $0.009 \%$ for NsZnO- 1 and $0.007 \%$ for NsZnO-2: these low values confirm that the release is a surface phenomenon.

The higher $\mathrm{Zn}^{2+}$ ion release ability of $\mathrm{NsZnO}-1$ is in agreement with the higher antibacterial activity of this carrier (Figure 6).

The in vitro ibuprofen release study was aimed at verifying the possibility of releasing the drug from IBU@NsZnO-1 and IBU@NsZnO-2 systems, assessing the lack of complete irreversible trapping of drug molecules in the carrier. The same test was carried out with crystalline ibuprofen for comparison.

Figure 8 shows the cumulative release curves of ibuprofen. The percentage of drug released in $6 \mathrm{~h}$ was 68\% for IBU@NsZnO-2,44\% for IBU@NsZnO-1, and 57\% for crystalline ibuprofen.

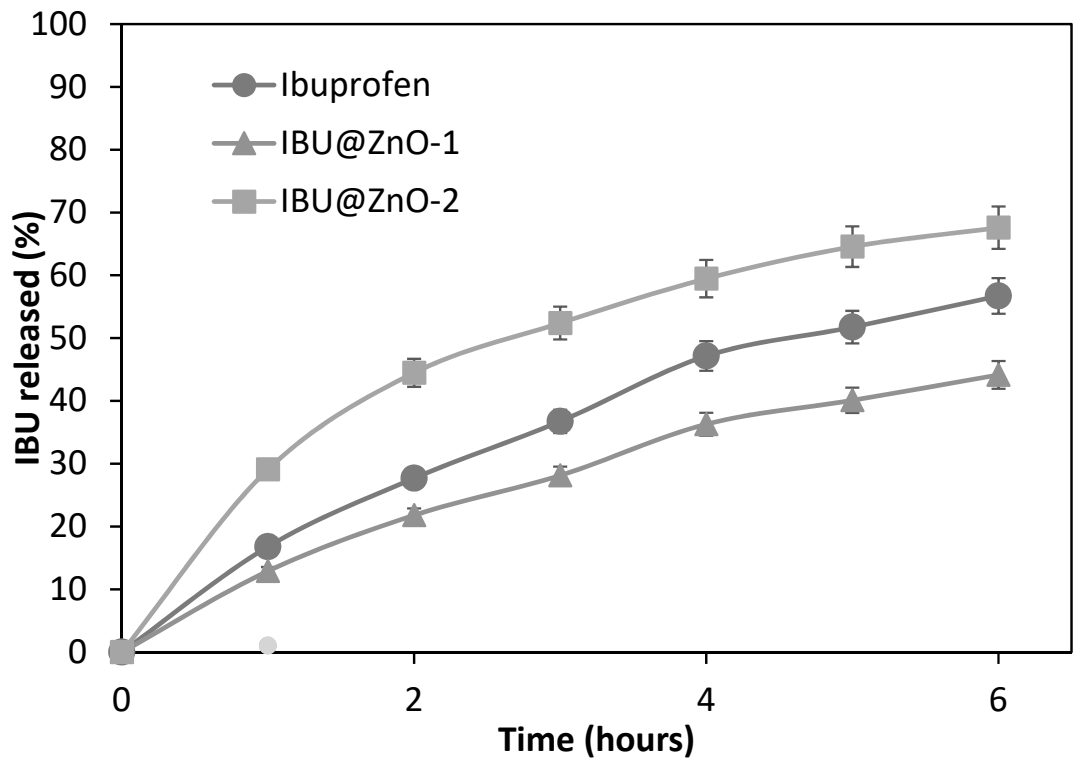

Figure 8. In vitro release profile of ibuprofen from IBU@NsZnO-1, IBU@NsZNO-2, and crystalline ibuprofen. 
These data reveal that both NsZnO-1 and NsZnO-2 were able to act as carriers for ibuprofen delivery. The different percentage of IBU released from the two materials may be ascribed to the different morphology and pore volume, which affect the distribution of drug molecules in the carrier and their diffusion to the receiving solution.

In conclusion, this preliminary in vitro release test showed that ibuprofen adsorbed on the NsZnO- 1 and $\mathrm{NsZnO}-2$ by scCO 2 can be delivered, confirming the potential role of these nanostructures as drug delivery systems, as previously observed in the case of clotrimazole [26].

\section{Conclusions}

A feasibility study was conducted to investigate the possibility of developing a green multifunctional device for wound healing applications. Two multifunctional drug delivery systems based on nanostructured $\mathrm{ZnO}$ were prepared by means of non-toxic and organic-solvent free procedures.

The antimicrobial properties of the $\mathrm{ZnO}$ carriers were investigated against both Gram-positive and Gram-negative bacterial strains, such as $S$. aureus and K. pneumoniae, as well as against C. albicans. As a whole, the results indicated that the two $\mathrm{ZnO}$ nanostructures exhibited the following activity: S. aureus $>$ C. albicans $>$ K. pneumoniae.

Moreover, an in vitro $\mathrm{Zn}^{2+}$ release study was carried out. A correlation between the antimicrobial activity, the physico-chemical properties (specific surface area and crystal size) of nanostructured $\mathrm{ZnO}$ and the $\mathrm{Zn}^{2+}$ ion release was found.

For the first time ibuprofen was successfully loaded on the nanostructured $\mathrm{ZnO}$ carriers with a supercritical $\mathrm{CO}_{2}$-mediated drug impregnation process. The drug-loaded amount was observed to depend on the specific surface area and the pore volume of the carrier and up to $14 \% w / w$ of ibuprofen in its amorphous form was obtained inside the final drug delivery system. A preliminary drug release test showed that up to $68 \%$ of the loaded ibuprofen could be delivered to a biological medium, confirming the feasibility of using nanostructured $\mathrm{ZnO}$ as a multifunctional antimicrobial drug carrier.

Supplementary Materials: The following are available online at http:/ / www.mdpi.com/2079-4991/9/3/407/ s1, Figure S1: Section A: TG curves of NsZnO-1 and IBU@NsZnO-1; Section B: TG curves of NsZnO-2 and IBU@NsZnO-2.

Author Contributions: Conceptualization, F.L. and B.O.; Investigation, F.L., R.C. (Roberta Cataldo), S.S.Y.M., S.R., and N.M.; Methodology, L.M., M.B., and N.M.; Resources, L.M., R.C. (Roberta Cavalli), and B.O.; Supervision, B.O.; Validation, L.M., S.R., V.T., and R.C. (Roberta Cavalli); Writing—original draft, F.L. and M.B.; Writing—review and editing, S.S.Y.M., M.B., V.T., and B.O.

Funding: This research received no external funding.

Conflicts of Interest: The authors declare no conflict of interest.

\section{References}

1. Kolodziejczak-Radzimska, A.; Jesionowski, T. Zinc oxide-from synthesis to application: A review. Materials (Basel) 2014, 7, 2833-2881. [CrossRef] [PubMed]

2. Wang, Z.L.; Kong, X.Y.; Ding, Y.; Gao, P.; Hughes, W.L.; Yang, R.; Zhang, Y. Semiconducting and piezoelectric oxide nanostructures induced by polar surfaces. Adv. Funct. Mater. 2004, 14, 943-956. [CrossRef]

3. Wang, Z.L. Novel nanostructures of $\mathrm{ZnO}$ for nanoscale photonics, optoelectronics, piezoelectricity, and sensing. Appl. Phys. A Mater. Sci. Process. 2007, 88, 7-15. [CrossRef]

4. Pasquet, J.; Chevalier, Y.; Couval, E.; Bouvier, D.; Bolzinger, M.A. Zinc oxide as a new antimicrobial preservative of topical products: Interactions with common formulation ingredients. Int. J. Pharm. 2015, 479, 88-95. [CrossRef] [PubMed]

5. Sirelkhatim, A.; Mahmud, S.; Seeni, A.; Kaus, N.H.M.; Ann, L.C.; Bakhori, S.K.M.; Hasan, H.; Mohamad, D. Review on zinc oxide nanoparticles: Antibacterial activity and toxicity mechanism. Nano-Micro Lett. 2015, 7, 219-242. [CrossRef] [PubMed] 
6. Mirzaei, H.; Darroudi, M. Zinc oxide nanoparticles: Biological synthesis and biomedical applications. Ceram. Int. 2017, 43, 907-914. [CrossRef]

7. Zafar, R.; Zia, K.M.; Tabasum, S.; Jabeen, F.; Noreen, A.; Zuber, M. Polysaccharide based bionanocomposites, properties and applications: A review. Int. J. Biol. Macromol. 2016, 92, 1012-1024. [CrossRef] [PubMed]

8. Díez-Pascual, A.M.; Díez-Vicente, A.L. Wound healing bionanocomposites based on castor oil polymeric films reinforced with chitosan-modified ZnO nanoparticles. Biomacromolecules 2015, 16, 2631-2644. [CrossRef] [PubMed]

9. Yadollahi, M.; Gholamali, I.; Namazi, H.; Aghazadeh, M. Synthesis and characterization of antibacterial carboxymethyl Chitosan/ZnO nanocomposite hydrogels. Int. J. Biol. Macromol. 2015, 74, 136-141. [CrossRef] [PubMed]

10. Staneva, D.; Atanasova, D.; Vasileva-Tonkova, E.; Lukanova, V.; Grabchev, I. A cotton fabric modified with a hydrogel containing ZnO nanoparticles. Preparation and properties study. Appl. Surf. Sci. 2015, 345, 72-80. [CrossRef]

11. Raguvaran, R.; Manuja, B.K.; Chopra, M.; Thakur, R.; Anand, T.; Kalia, A.; Manuja, A. Sodium alginate and gum acacia hydrogels of $\mathrm{ZnO}$ nanoparticles show wound healing effect on fibroblast cells. Int. J. Biol. Macromol. 2017, 96, 185-191. [CrossRef] [PubMed]

12. Jones, N.; Ray, B.; Ranjit, K.T.; Manna, A.C. Antibacterial activity of ZnO nanoparticle suspensions on a broad spectrum of microorganisms. FEMS Microbiol. Lett. 2008, 279, 71-76. [CrossRef] [PubMed]

13. Khezerlou, A.; Alizadeh-sani, M.; Azizi-lalabadi, M.; Ehsani, A. Microbial Pathogenesis Nanoparticles and their antimicrobial properties against pathogens including bacteria, fungi, parasites and viruses. Microb. Pthogenes. 2018, 123, 505-526. [CrossRef] [PubMed]

14. Pasquet, J.; Chevalier, Y.; Couval, E.; Bouvier, D.; Noizet, G.; Morlière, C.; Bolzinger, M.A. Antimicrobial activity of zinc oxide particles on five micro-organisms of the Challenge Tests related to their physicochemical properties. Int. J. Pharm. 2014, 460, 92-100. [CrossRef] [PubMed]

15. Kumar, R.; Umar, A.; Kumar, G.; Nalwa, H.S. Antimicrobial properties of ZnO nanomaterials: A review. Ceram. Int. 2017, 43, 3940-3961. [CrossRef]

16. Agren, M.S.; Mirastschijski, U. The release of zinc ions from and cytocompatibility of two zinc oxide dressings. J. Wound Care 2004, 13, 367-369. [PubMed]

17. Lansdown, A.B.G.; Mirastschijski, U.; Stubbs, N.; Scanlon, E.; Ågren, M.S. Zinc in wound healing: Theoretical, experimental, and clinical aspects. Wound Repair Regen. 2007, 15, 2-16. [CrossRef] [PubMed]

18. Morgado, P.I.; Miguel, S.P.; Correia, I.J.; Aguiar-Ricardo, A. Ibuprofen loaded PVA/chitosan membranes: A highly efficient strategy towards an improved skin wound healing. Carbohydr. Polym. 2017, 159, 136-145. [CrossRef] [PubMed]

19. Price, P.; Fogh, K.; Glynn, C.; Krasner, D.L.; Osterbrink, J.; Sibbald, R.G. Why combine a foam dressing with ibuprofen for wound pain and moist wound healing? Int. Wound J. 2007, 4, 1-3. [CrossRef] [PubMed]

20. Xiong, H.M. ZnO nanoparticles applied to bioimaging and drug delivery. Adv. Mater. 2013, 25, 5329-5335. [CrossRef] [PubMed]

21. Girotra, P.; Singh, S.K.; Nagpal, K. Supercritical fluid technology: A promising approach in pharmaceutical research. Pharm. Dev. Technol. 2012, 18, 22-38. [CrossRef] [PubMed]

22. Champeau, M.; Thomassin, J.M.; Tassaing, T.; Jérôme, C. Drug loading of polymer implants by supercritical $\mathrm{CO}_{2}$ assisted impregnation: A review. J. Control. Release 2015, 209, 248-259. [CrossRef] [PubMed]

23. Gurikov, P.; Smirnova, I. Amorphization of drugs by adsorptive precipitation from supercritical solutions: A review. J. Supercrit. Fluids 2018, 132, 105-125. [CrossRef]

24. Banchero, M.; Ronchetti, S.; Manna, L. Characterization of ketoprofen/methyl- $\beta$-cyclodextrin complexes prepared using supercritical carbon dioxide. J. Chem. 2013, 2013, 583952. [CrossRef]

25. Rudrangi, S.R.S.; Trivedi, V.; Mitchell, J.C.; Wicks, S.R.; Alexander, B.D. Preparation of olanzapine and methyl- $\beta$-cyclodextrin complexes using a single-step, organic solvent-free supercritical fluid process: An approach to enhance the solubility and dissolution properties. Int. J. Pharm. 2015, 494, 408-416. [CrossRef] [PubMed]

26. Leone, F.; Gignone, A.; Ronchetti, S.; Cavalli, R.; Manna, L.; Banchero, M.; Onida, B. A green organic-solvent-free route to prepare nanostructured zinc oxide carriers of clotrimazole for pharmaceutical applications. J. Clean. Prod. 2018, 172, 1433-1439. [CrossRef] 
27. Bushra, R.; Aslam, N. An overview of clinical pharmacology of Ibuprofen. Oman Med. J. 2010, 25, $155-161$. [PubMed]

28. Irvine, J.; Afrose, A.; Islam, N. Formulation and delivery strategies of ibuprofen: challenges and opportunities. Drug Dev. Ind. Pharm. 2018, 44, 173-183. [CrossRef]

29. Gignone, A.; Manna, L.; Ronchetti, S.; Banchero, M.; Onida, B. Microporous and Mesoporous Materials Incorporation of clotrimazole in Ordered Mesoporous Silica by supercritical $\mathrm{CO}_{2}$. Microporous Mesoporous Mater. 2014, 200, 291-296. [CrossRef]

30. Reference Method for Broth Dilution Antifungal Susceptibility Testing of Yeasts, Approved Standard, 3rd ed.; Clinical and Laboratory Standards Institute: Wayne, PA, USA, 2008; Volume 28.

31. Methods for Dilution Antimicrobial Susceptibility Tests for Bacteria That Grow Aerobically, Approved Standard, 9th ed.; Clinical and Laboratory Standards Institute: Wayne, PA, USA, 2012; Volume 32.

32. Mandras, N.; Nostro, A.; Roana, J.; Scalas, D.; Banche, G.; Ghisetti, V.; Del Re, S.; Fucale, G.; Cuffini, A.M.; Tullio, V. Liquid and vapour-phase antifungal activities of essential oils against Candida albicans and non-albicans Candida. BMC Complement. Altern. Med. 2016, 16, 1-7. [CrossRef] [PubMed]

33. Wahid, F.; Yin, J.J.; Xue, D.D.; Xue, H.; Lu, Y.S.; Zhong, C.; Chu, L.Q. Synthesis and characterization of antibacterial carboxymethyl Chitosan/ZnO nanocomposite hydrogels. Int. J. Biol. Macromol. 2016, 88, 273-279. [CrossRef] [PubMed]

34. Kakiuchi, K.; Hosono, E.; Kimura, T.; Imai, H.; Fujihara, S. Fabrication of mesoporous ZnO nanosheets from precursor templates grown in aqueous solutions. J. Sol-Gel Sci. Technol. 2006, 39, 63-72. [CrossRef]

35. Anas, M.; Gönel, A.G.; Bozbag, S.E.; Erkey, C. Thermodynamics of Adsorption of Carbon Dioxide on Various Aerogels. J. CO2 Util. 2017, 21, 82-88. [CrossRef]

36. Graedel, T.E. Corrosion Mechanisms for Zinc Exposed to the Atmosphere. J. Electrochem. Soc. 1989, 136, 193C-203C. [CrossRef]

37. Ramani, M.; Ponnusamy, S.; Muthamizhchelvan, C.; Marsili, E. Amino acid-mediated synthesis of zinc oxide nanostructures and evaluation of their facet-dependent antimicrobial activity. Colloids Surf. B Biointerfaces 2014, 117, 233-239. [CrossRef] [PubMed]

38. Sun, Q.; Li, J.; Le, T. Zinc Oxide Nanoparticle as a Novel Class of Antifungal Agents: Current Advances and Future Perspectives. J. Agric. Food Chem. 2018, 66, 11209-11220. [CrossRef] [PubMed]

39. Reddy, K.M.; Feris, K.; Bell, J.; Hanley, C.; Punnoose, A. Selective toxicity of zinc oxide nanoparticles to prokaryotic and eukaryotic systems. Appl. Phys. Lett. 2007, 24, 213902-1-213902-3. [CrossRef] [PubMed]

40. Tayel, A.A.; El-Tras, W.F.; Moussa, S.; El-Baz, A.F.; Mahrous, H.; Salem, M.F.; Brimer, L. Antibacterial action of zinc oxide nanoparticles against foodborne pathogens. J. Food Saf. 2011, 31, 211-218. [CrossRef]

41. Lipovsky, A.; Nitzan, Y.; Gedanken, A.; Lubart, R. Antifungal activity of ZnO nanoparticles-the role of ROS mediated cell injury. Nanotechnology 2011, 22, 105101. [CrossRef] [PubMed] 